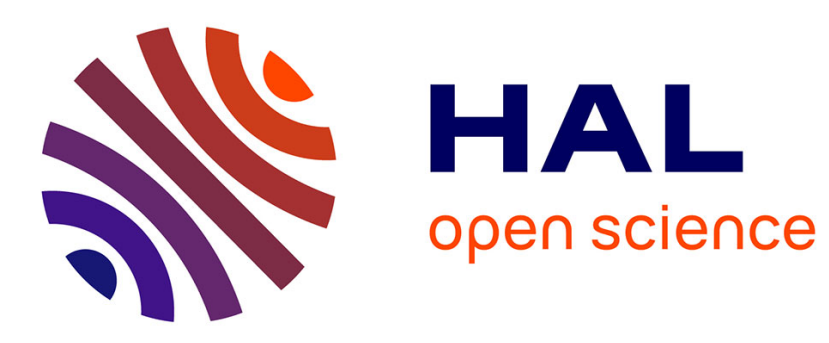

\title{
Polysaccharide Chemistry in Drug Delivery, Endocrinology, and Vaccines
}

Aimen Khalid, Asim -ur-rehman, Naveed Ahmed, Iqra Chaudhery, Meneerah Al-jafary, Ebtesam Abdullah Al-suhaimi, Mohamad Tarhini, Noureddine Lebaz, Abdelhamid Elaissari

\section{To cite this version:}

Aimen Khalid, Asim -ur-rehman, Naveed Ahmed, Iqra Chaudhery, Meneerah Al-jafary, et al.. Polysaccharide Chemistry in Drug Delivery, Endocrinology, and Vaccines. Chemistry - A European Journal, 2021, 27 (33), pp.8437-8451. 10.1002/chem.202100204 . hal-03225264

\section{HAL Id: hal-03225264 \\ https://hal.science/hal-03225264}

Submitted on 1 Jun 2021

HAL is a multi-disciplinary open access archive for the deposit and dissemination of scientific research documents, whether they are published or not. The documents may come from teaching and research institutions in France or abroad, or from public or private research centers.
L'archive ouverte pluridisciplinaire HAL, est destinée au dépôt et à la diffusion de documents scientifiques de niveau recherche, publiés ou non, émanant des établissements d'enseignement et de recherche français ou étrangers, des laboratoires publics ou privés. 


\section{Polysaccharide Chemistry in Drug Delivery, Endocrinology, and Vaccines}

Aimen Khalid,[a] Asim-ur-Rehman,[a] Naveed Ahmed,[a] Iqra Chaudhery,[a] Meneerah A. Al-Jafary,[b]

Ebtesam Abdullah Al-Suhaimi,[b] Mohamad Tarhini,[c] Noureddine Lebaz,[d] and Abdelhamid

Elaissari*[c]

[a] A. Khalid, Dr. Asim-ur-Rehman, Dr. N. Ahmed, I. Chaudhery Department of Pharmacy, Faculty of Biological Sciences Quaid-i-Azam University, 45320, Islamabad (Pakistan)

[b] Dr. M. A. Al-Jafary, Prof. E. A. Al-Suhaimi Department of Biology, College of Science and Institute for Research and Medical Consultations (IRMC) Imam Abdulrahman Bin Faisal University, 31441 Dammam (Saudi Arabia)

[c] Dr. M. Tarhini, Dr. A. Elaissari Univ Lyon, University Claude Bernard Lyon-1 CNRS, ISA-UMR 5280, 69622 Villeurbanne (France) E-mail: Abdelhamid.elaissari@univ-lyon1.fr

[d] Dr. N. Lebaz Univ Lyon, University Claude Bernard Lyon-1 CNRS, LAGEPP-UMR 5007, 69100

Villeurbanne (France)

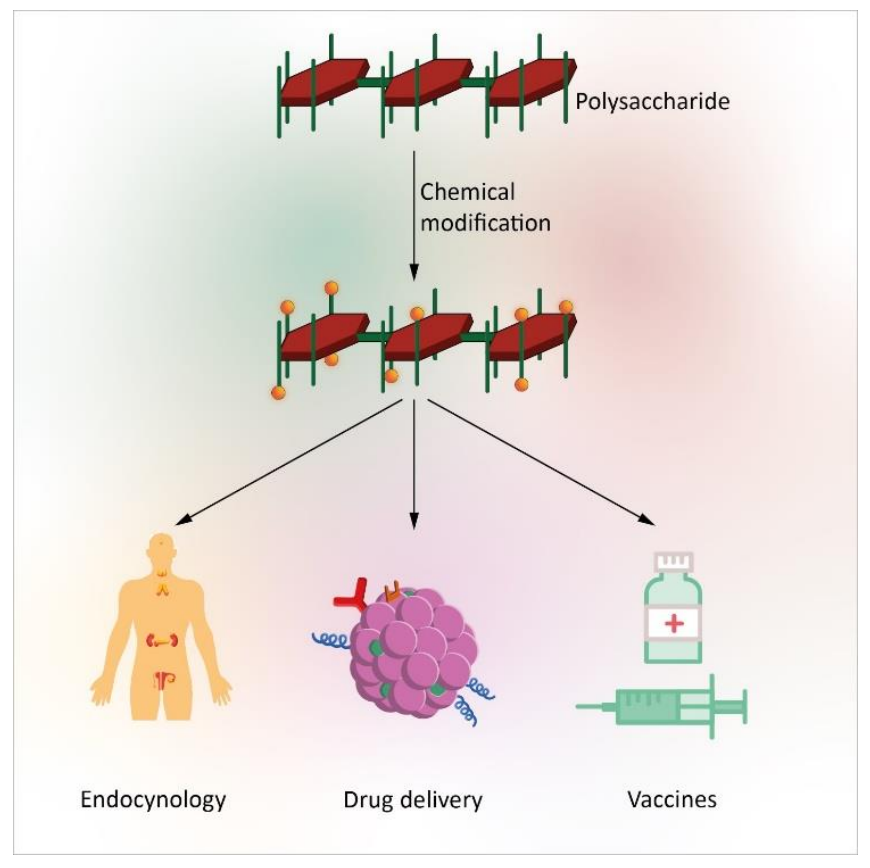

\section{Abstract}

Polysaccharides, due to their outstanding proper ties, have attracted the attention of researchers, working in the biomedical field and especially of those working in drug delivery. Modified/functionalized polysaccharides further increase the importance for various applications. Delivery of therapeutics for diverse ailments in different endocrine glands and hormones safely, is a focal point of researchers working in the field. Among the routes followed, the transdermal route is preferred due to non-exposure of active moieties to the harsh gastric environment and first-pass metabolism. This review starts with the overview of polysaccharides used for the delivery of various therapeutic agents. Advantages of polysaccharides used in the transdermal route are addressed in detail. Types of polysaccharides will be elaborated through 
examples, and in this context, special emphasis will be on the polysaccharides being used for synthesis of the membranes/ films. Techniques employed for their modification to design novel carriers for therapeutics delivery will also be discussed. The review will end with a brief discussion on recent developments and future perspectives for delivery of therapeutic agents, and vaccine development.

\section{Introduction}

Hydrogels are hydrophilic polymeric networks, swollen when come in contact with water. They are considered as colloidal gels in which water acts as a dispersion medium. These hydrophilic gels are formed by the cross linking of macromolecules which can be categorized as physical or chemical crosslinking. Sometimes both forms of crosslinking co-exist in the same networks. Because of the ability to retain significant amount of water, hydrogels are considered useful in many biomedical fields. ${ }^{[1]}$ Numerous polymers have been proposed for hydrogels preparation, but the importance of polysaccharides has gained the attention of researchers in the pharmaceutical field. ${ }^{[2]}$ Polysaccharides are abundant in nature and obtained from renewable sources such as algae, plants and through recombinant DNA techniques. Polysaccharides have diverse composition and properties, and their simpler production methods makes them economical rather than other synthetic polymers.

Natural polysaccharides are mostly used for drug delivery because of their biocompatibility and biodegradability. Among all polysaccharides, sodium alginate, dextran, chitosan, especially hyaluronic acids (HA), have gained more importance and used in nanoformulation. These polymers possess physical and biological advantages when used in combination with other polymers. ${ }^{[3]}$ This review will discuss the chemical modifications of polysaccharide, followed by their recent application in endocrinology, drug delivery, and vaccine research. While many polysaccharide will be mentioned on this review, the focus will be on the four previously mentioned natural ones. Their structure can be found in figure 1.
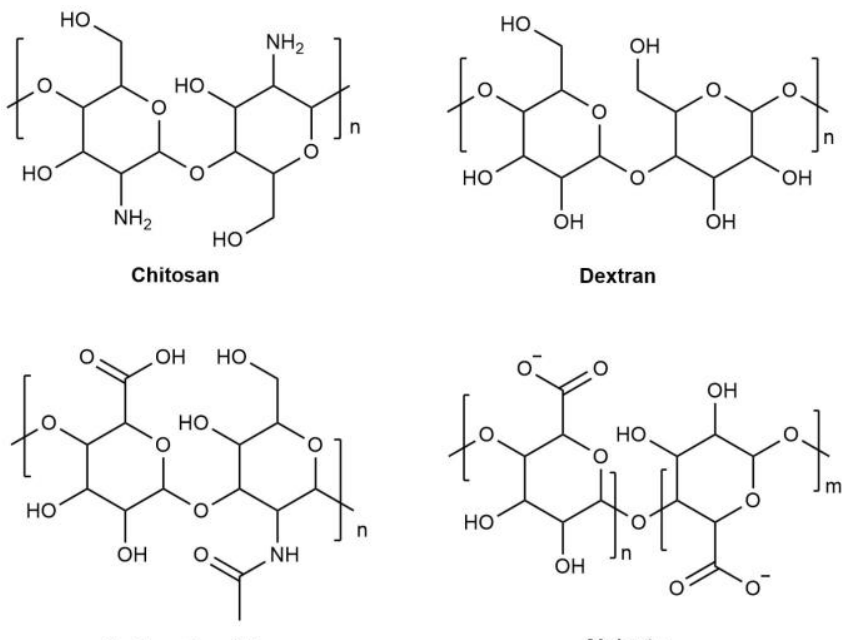

Hyaluronic acid

Alginate

Figure 1 Examples of polysaccharides. 


\section{Chemical modifications of polysaccharides}

Molecular amendments in structures of different polysaccharides by varying their chemical, physical, and biological nature can be achieved to obtain their various derivatives. By using different appropriate methods, structural changes alter the physicochemical properties of polysaccharides and enable to study their structure-activity relationships. Nowadays, researchers have studied distinct features of modified polysaccharides due to their ideal properties and better pharmacological actions. ${ }^{[4]}$ But the problem associated with their limited development is the lack of extensive research related to their formulation methods. Following is the chemical modification of some well-known polysaccharides and briefly reports on their medicinal therapeutic uses in disease management.

\section{Graft polymerization}

Grafting is the formation of graft, a functional derivative formed by covalent binding of certain molecule with the polymer backbone. This technique is extensively used with chitosan due to its interesting properties to enhance its solubility for pharmaceutical applications. ${ }^{[5]}$ Chitosan has two reactive groups, a hydroxyl groups on $C_{3}$ and $C_{46}$ carbons (acetylated or deacetylated units of chitosan) and free amine groups on deacetylated units. In recent years, different initiator systems have been developed to start the graft copolymerization such as potassium persulphate (PPS), thiocaronationpotassium bromate (TCPB), ammonium persulfate (APS), 2,2'-azobisisobutyronitrile (AIBN), ceric ammonium chloride (CAN) and ferrous ammonium sulfate (FAS). ${ }^{[6]}$ Grafting parameters such as grafting efficiency and percentage are greatly affected by the initiator concentration and type, monomer concentration, reaction time and temperature. The properties of grafted copolymers are generally controlled by characteristics of side chains, including molecular structure, number, and length. Numerous researchers have studied the influence of these variables in the formation of grafted chitosan. ${ }^{[7]}$ Different approaches for grafting of chitosan are discussed in separate sections.

\section{Grafting initiated with free radicals}

In last few decades, graft copolymerization of vinyl monomers with chitosan using free radicals as initiator has attracted a lot of interest. Sun et al. used ammonium persulfate (APS) as initiator to prepare carboxymethyl chitosan-grafted methacrylic acid (MAA) in aqueous solution. ${ }^{[8]}$ The effects of methacrylic acid, APS, reaction time and temperature on graft copolymerization were studied by determining the grafting efficiency and percentage. Improved water solubility was observed in grafted chitosan. Similarly, Xie et al. used APS to prepare hydroxy-propyl chitosan-grafted MAA and the obtained results showed good water solubility of this derivative. ${ }^{[9]}$

The graft copolymerization of maleic acid sodium (MAS) onto hydroxypropyl chitosan and carboxymethyl chitosan using APS initiator was reported. ${ }^{[10]}$ The antioxidant activity of these derivatives was evaluated as superoxide anion scavengers by chemiluminescence technology. Grafted chitosan improved scavenging ability against superoxide anions as compared to simple pure chitosan. Hydroxypropyl grafted chitosan has high superoxide anion scavenging ability due to hydroxyl group. Chitosan acylation with maleic anhydride removes carbon-carbon double bonds which are available for polymerization. The derivatives copolymerization with acrylamide in water using APS has been used to obtain three-dimensional crosslinked product. ${ }^{[6]}$ Resulting copolymers swelling in water was increased up to 20-150 times than the natural one. 
Grafting of vinyl monomers onto chitosan can be carried out by CAN and PPS initiator systems. Polyvinyl acetate (PVAC), a water-resistant polymer, improves the properties of chitosan. ${ }^{[11]}$ After $2 \mathrm{~h}$ of reaction at $60^{\circ} \mathrm{C}, 70-80 \%$ of monomer conversion was found and by increasing the amount of chitosan, grafting efficiency has also been improved. Many experimental evidence showed that chitosan molecules not only took part in graft copolymerization but they also act as surfactant and provide stability to dispersed molecules. Moreover, incorporation of PVAc to chitosan chains makes them water resistant thus decreases their toughness and water absorption capacity.

Another renowned hydrogel forming polymer, polyacrylic acid was reported in literature for graft modification of chitosan. ${ }^{[12]}$ The grafting was performed using FAS and PPS as combined redox initiator system. The grafting efficiency obtained in this work was around $52 \%$. It is high enough when compared with vinyl monomer. This result showed that in homogenous system grafting reaction takes place in the whole substrate and not in one molecule. Cheaburu-Yilmaz et al. have reported the effect of temperature and other reaction conditions on grafting efficiency of 2-hydroxyethyl methacrylate (HEMA) onto chitosan. ${ }^{[13]}$ Conversion of HEMA monomer was found to be of $75 \%$, with increased hydrophilicity and therefore may be used in textile finishes for increasing the hydrophilicity of synthetic fibers.

\section{Enzymatic grafting}

Many beneficial characteristics of enzymes grafting in polymer modification and synthesis were reported in literature. ${ }^{[14,15]}$ One of the major environmental advantages of using enzymes is their selectivity, which may be utilized to eradicate the need for protection steps. Remarkable increase in water solubility because of improved adhesive and $\mathrm{pH}$ sensitive properties were reported after enzymatic modification. It has been described that grafting of phenolic compounds onto chitosan under basic conditions confers it enhanced water solubility (Figure 2). ${ }^{[15]}$ Tyrosinase converts phenolic substrates into electrophilic oquinones and chitosan could also be modified with natural products like chlorogenic acid under acidic conditions. Modified chitosan is soluble under both basic and acidic conditions even with low degree of modification.

Due to complex nature of quinone, its chemistry remains poorly characterized. Quinone undergoes two different reactions to give either Michael type adducts or Schiff bases. Therefore, quinone undertakes any types of reactions with amines as well. It can also undergo oligomers formation with other quinones.

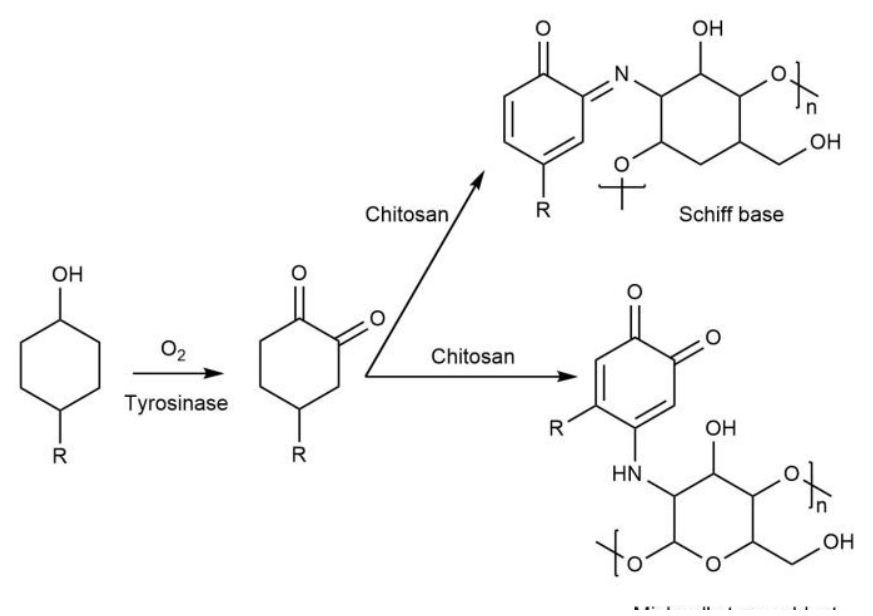

Figure 2 Enzymatic grafting with tyrosinase on chitosan. 
Grafting hexyloxyphenol onto chitosan using tyrosinase as a catalyst was also investigated ${ }^{[16]}$. Under homogenous conditions phenol is converted into reactive o-quinone in presence of tyrosinase.

\section{Grafting using cations}

Few years ago, Aljawish et.al performed experiments to show that cationic polymerization can also be used for chitosan grafting. ${ }^{[16]}$ Chitosan grafting was performed under controlled weight distribution with living poly-2-methyl-2-oxazoline and poly-isobutyl vinyl ether cation. Researchers investigated how the number of moles in grafted polymers was affected by molecular weight of living polymer cation. By increasing the molecular weight of living polymer cation, the mole number of grafted polymer chain was found to decrease, due to steric hindrance of functional groups of chitosan. Moreover, increasing the grafting percentage, the viscosity of resulting polymer was enhanced. The obtained graft polymer was also found to be more water soluble.

\section{Grafting using radiation}

Recently, natural polysaccharides are grafted by using radiation method. At room temperature, chitosan grafting with polystyrene using Co $y$-irradiation was reported. ${ }^{[17,18]}$ Effect of various conditions like solvent nature, oxygen level and adsorbed dose on grafting was analyzed. Results indicate that by increasing the adsorbed dose, grafting yield increases. Radiation grafting of chitosan with N, N'-dimethyl-aminoethylmethacrylate was also discussed by Montes et al. ${ }^{[19]}$ The rate of grafting and homo-polymerization were found to be affected by different parameters such as concentration of monomer, dose rate of radiation, solvent composition, and total radiation time. In this study, it was found that by selecting appropriate grafting conditions, the desired level of grafting of DMAEMA onto chitosan films was achieved.

Graft copolymerization of butyl acrylate onto chitosan using $\gamma$-irradiation was reported by Li et al. ${ }^{[20]}$ They observed that the increase in grafting percentage is directly related to total dose and monomer concentration, but inversely related to chitosan concentration and reaction temperature.

\section{Esterification}

Esterification is the substitution reaction that occurs between a hydroxyl and a carboxy group leading to the formation of an ester bond. Polysaccharides possessing one or both groups can be esterified to enhance their properties. For instance, the carboxylic group of HA can be involved in and esterification reaction using diazomethane. This method was first reported by Jeanloz and Forchielli. ${ }^{[21]}$ DMSO was also used in reaction as organic solvent to form HA-TBA (Hyaluronic acid-tetrabutylammonium (TBA) salt. The use of trimethylsilyl diazomethane (TMSD) as carboxylic group activator for the preparation of methyl ester of HA was reported by Hirano et al. ${ }^{[22]}$ The reaction of HA with TMSD forms an intermediate, which

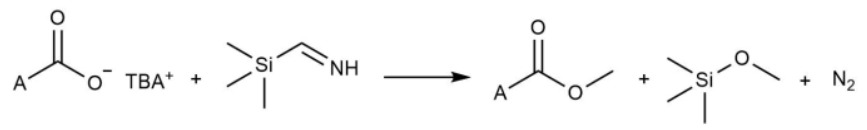

Figure 3 Esterification of HA using TMSD

then recovers methyl ester by reacting with acetic acid (Figure 3). On the other hand, Borzacchiello patented carboxylic group esterification by alkylation using bromides or alkyl iodides. ${ }^{[23]}$ researcher used a similar technique over 24 hours and synthesized amphiphilic HA esters. ${ }^{[24]}$

Moreover, the hydroxyl group of HA can also be a target for esterification. Under alkaline conditions (pH 9) in water, Tommeraas and Eenschooten reported the use of alkyl succinic anhydride for modification of 
$H A$, such as octenyl succinic anhydride (OSA). ${ }^{[25]}$ Ester bonds are formed by reaction of the hydroxyl group of HA with anhydride as showed in (Figure 4a). Eenschooten later used the experimental design to optimize the parameters and $43 \%$ substitution could be attained by using OSA, 50 times more than pure HA. ${ }^{[26]}$

Recently, a novel method for HA modification was reported in which the ester bond is formed by grafting an acyl-chloride activated carboxylate compound onto HA hydroxyl groups (Figure 4b). ${ }^{[27]}$ First, chloroacylation is achieved with thionyl chloride to activate the carboxyl group of the compounds which further to be grafted and reacted at room temperature with HA. Researchers grafted poly (lactic acid) (PLA) oligomers by this method. Organic solvent (DMSO) was used in this reaction and HA was converted into salts of cetyltrimethyl-ammonium bromide. ${ }^{[28]}$

The carboxyl group of alginates was also used for an esterification reaction. The hydrophobic nature is increased by the addition of alkyl groups to the backbone of native alginates. ${ }^{[24,29-31]}$ In the presence of a catalyst, direct esterification with alcohol can be achieved to modify native alginates.

Researchers prepared novel water-soluble amphiphilic cholesteryl ester of alginate at room temperature for $24 \mathrm{~h}$, the reaction was carried out in presence of $4-\left(\mathrm{N}, \mathrm{N}^{\prime}\right.$-dimethylamino) as a catalyst and $\mathrm{N}, \mathrm{N}^{\prime}$ dicyclohexylcarbodiimide as a coupling agent. ${ }^{[32]}$ The studies showed that amphiphilic cholesteryl ester of alginate can self-assemble into more compact and stable nanoaggregates, when compared with parent sodium alginates. Researchers reported esterification of $\mathrm{Na}$-alginates with butanol using concentrated $\mathrm{H}_{2} \mathrm{SO}_{4}$ as a catalyst for $18 \mathrm{~h} .{ }^{[33]}$ The study shows that the novel material has the ability to encapsulate both hydrophobic and hydrophilic molecules. Significantly, all nontoxic and gelling properties of native

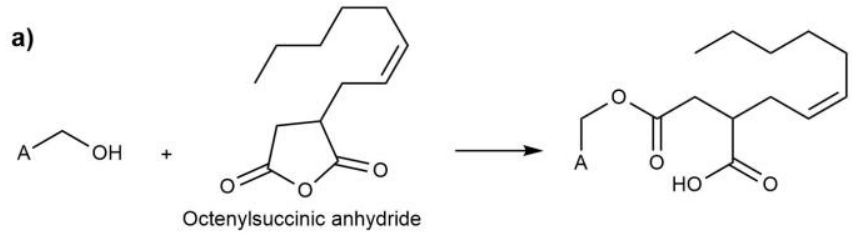

b)

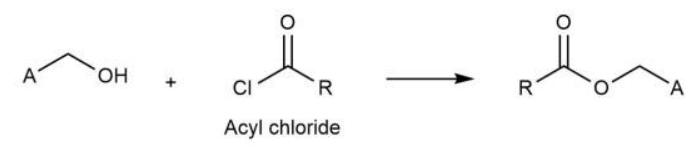

Figure 4 (a) Modification of -OH group of HA with octenyl succinic

alginates have been retained after such modifications.

\section{Amidation}

Amidation using carbodiimides, one of the most commonly used methods for HA modification in which 1-

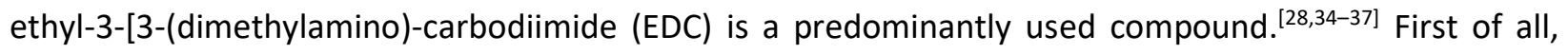
Danishefsky and Siskovic reported conversion of the carboxyl group of polysaccharides into amides. ${ }^{[38]}$ At $\mathrm{pH} 4.75$, they activate the carboxylic groups by using EDC, which then reacts with an ester of amino acid. Chromatography, infrared spectroscopy and electrometric titration were used for the detection of amide bonds, with 38.6 degree of substitution. 
The detail mechanism of reaction has been studied by Nakajima and Ikada. ${ }^{[39]}$ The first step is the activation of the carboxylic acid of HA by EDC, which forms an intermediate, $\mathrm{O}$-acyl isourea. In the second step, amine attacks on activated $\mathrm{HA}$ as a nucleophile, which results in amide bond formation (Figure 5a). However, intermediate o-acylisourea is highly reactive and it also reacts with water, and quickly arranges into stable by-product, $\mathrm{N}$-acyl urea, thus prevents further reactions with amines. The reaction is strongly $\mathrm{pH}$-dependent and both steps require different optimal $\mathrm{pH}$. Indeed, acidic media are best for carboxylic acid activation, using EDC. ${ }^{[40]}$ whereas, at basic $\mathrm{pH}$, amide bond formations are best performed. At such high $\mathrm{pH}, \mathrm{EDC}$ is rapidly hydrolyzed into $\mathrm{N}$-acyl urea by-product and no amidation occurs. Therefore, amines with high pKa values are not easily conjugated to HA by using this method.

Evidence of amidation with HA was shown by many researchers. All previous studies were negated by researchers demonstrating that no amide bond was formed between amino and carboxylic groups of hyaluronic acid. ${ }^{[38,39,41,42]}$ Protonated amine does not easily react with activated HA. As protonated amine group is not a nucleophile so, Kuo et al. anticipated that carbodiimides should be used as a reagent not as an activator. Therefore, carbodiimides were used to crosslink $\mathrm{HA}$ and form stable bis ( $\mathrm{N}$-acylurea) crosslinked gels (Figure 5b). Using dihydrazides in place of diamines, having much lower pKa values helps to attain higher coupling up to $56 \%{ }^{[43]}$ No crosslinking was observed after adding excess of adipic dihydrazides $(\mathrm{ADH})$ but dihydrazide bonds and single functionalization were formed (Figure 5a).

Similarly, Galant reported the modification of alginates by using 1-ethyl-3-(3-dimethylaminopropyl) carbodiimide hydrochloride $(E D C-H C l)$ as a coupling agent to form amide linkages between carboxylates moieties on alginate polymer backbone and amines containing molecules. ${ }^{[44]}$ In literature, the preparation of alginate derivatives through amide bond linkage has also been reported. ${ }^{[45-49]}$ The reaction is stated as: first, $\mathrm{pH}$ is adjusted to 3.4 by adding $\mathrm{HCl}$, then this solution was added into $\mathrm{EDC}-\mathrm{HCl}$. Octylamine was added into previous solution after $5 \mathrm{~min}$ of reaction and the mixture was stirred for $24 \mathrm{~h}$ at room temperature. The product was separated by precipitation and the polymers were recovered by filtration. The polymers were dialyzed against $\mathrm{H}_{2} \mathrm{O}$ and separated by freeze-drying.

Abu Rabeah reported alginate modification via amide linkage by using $\mathrm{N}$-(3-aminipropyl) pyrole as coupling agent same as above. ${ }^{[45]}$ Researchers found that the synthesized pyrrole-alginates can be proficiently electropolymerized, providing biocompatible host matrix that kept the enzyme by both electrochemical cross-linking and jellification up to $31 \%$ molar modification than the original one. 
a)
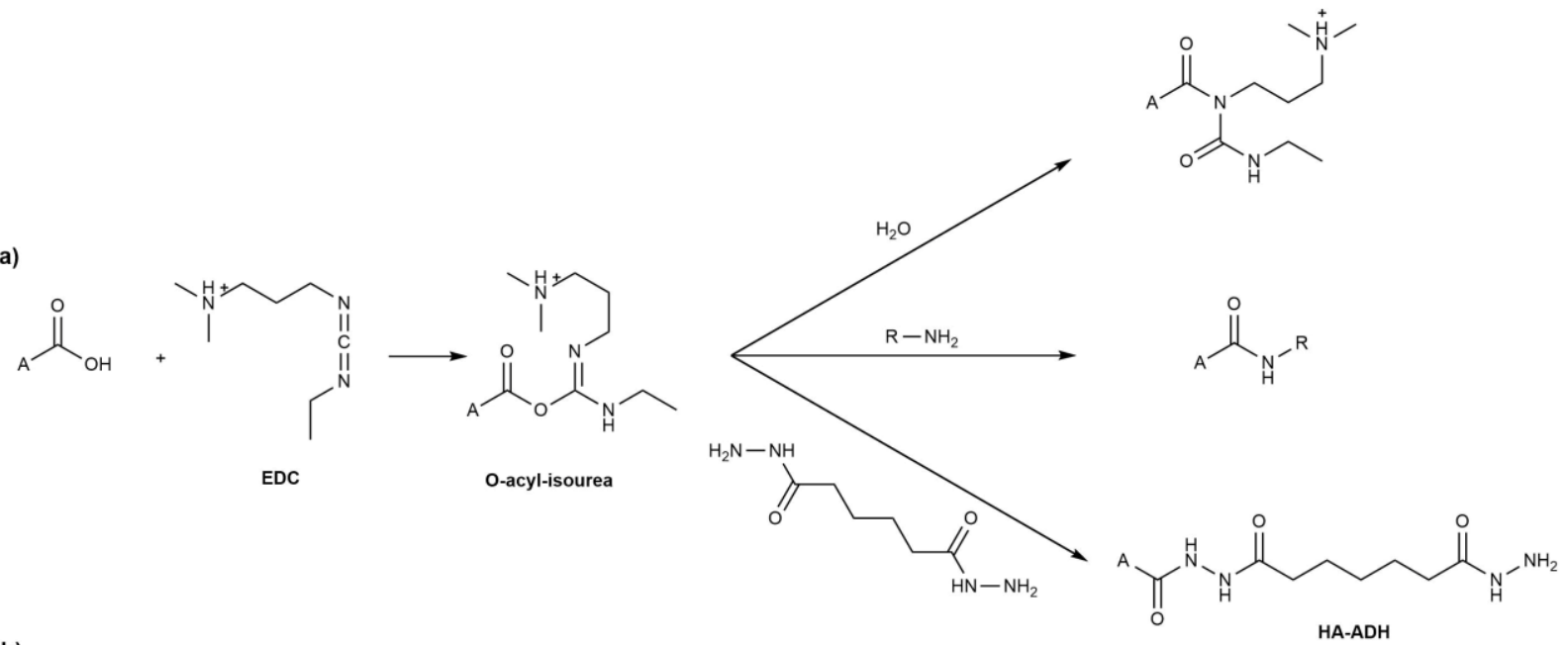

b)

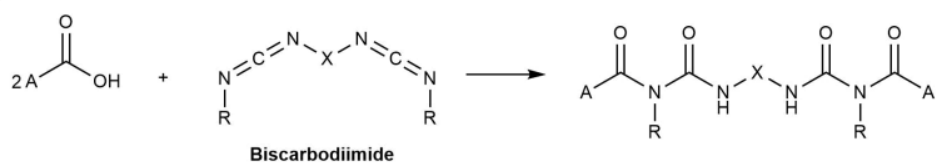

Figure 5 Mechanism of amidation of HA with EDC. And EDC with adipic dihydrazides (a), biscarbodiimides crosslinking of HA

(b)

\section{Oxidation}

In recent years, much attention has been paid on oxidation of alginates because oxidized alginates have more reactive groups and show faster degradation when used in controlled drug delivery systems. ${ }^{[50,51]}$ At $\mathrm{C}_{2}$ and $\mathrm{C}_{3}$ positions of uronic units of sodium alginate, oxidation reactions on hydroxyl groups are performed with sodium periodate. This leads to the formation of two aldehyde groups in each oxidized monomeric unit, by rupture of carbon-carbon bonds. Hence, large rotational freedom and new reactive groups along with the backbone are attained. During oxidation side reaction are prevented by exclusion of light and by varying the oxidant concentration, degree of alginate oxidation can be controlled. Oxidized alginates in aqueous solution of sodium alginate were synthesized by Gomez ${ }^{[52]}$. Alginates oxidation caused the breakage of $\mathrm{C}_{2}-\mathrm{C}_{3}$ bond and produced flexible polymer.

On the other hand, modification of Hyaluronic acid $(\mathrm{HA})$ with Sodium metaperiodate $\left(\mathrm{NaIO}_{4}\right)$ results in the formation of oxidized HA (OHA). OHA containing multiple aldehyde groups can easily react with the materials having amino functionality via formation of Schiff base linkage, resulting in the formation of $\mathrm{OHA}$ based hydrogel scaffolds for tissue engineering. The above discussion suggested that HA on reacting with sodium Meta periodates resulted in the generation of multiple aldehyde groups on carbohydrates (sugar units). The aldehydic moiety bearing positively charged carbon is very sensitive to nucleophilic attack which has sp2 hybridized orbit. This has been also reported that aldehyde can react with many polar groups due to the presence of negatively charged oxygen. These aldehydic groups are highly reactive towards amine groups containing polymers and can crosslink covalently resulting in the formation of Schiff base linkage (fig 2).

Hydrogels based on chitosan and OHA having temperature independent fast gelation property. It is reported that the hydrogel stability is due to the formation of covalent bond between aldehydic group of 
$\mathrm{OHA}$ and amine group of chitosan. These hydrogels were found to be biocompatible in nature having ability to retain N95\% of encapsulated cells, which can be suitable candidate for TE. Moreover, authors have also proposed that such types of hydrogel may find potential scope for their application in drug and gene delivery. ${ }^{[53,54]}$

Injectable hydrogel system based on chemo-selective grouping of four modified derivatives of HA (thiol, Hydrazide 2-dithiopyridyl and aldehydic) was developed by Kheirabadi et al. ${ }^{[55,56]}$ The formation of interpenetrating polymer network (IPN) takes place through formation of disulfide and hydrazone linkages by in situ mixing the aqueous solutions of thiol and 2-dithiopyridyl modified HA and Hydrazide and $\mathrm{OHA}$ respectively. The dispersion of magnetic nanoparticles helped in improving the mechanical Injectable hydrogel system based on chemo-selective grouping of four modified derivatives of HA (thiol, Hydrazide 2-dithiopyridyl and aldehydic) was developed by Kheirabadi et al. ${ }^{[55,56]}$ The formation of interpenetrating polymer network (IPN) takes place through formation of disulfide and hydrazone linkages by in situ mixing the aqueous solutions of thiol and 2-dithiopyridyl modified HA and Hydrazide and $\mathrm{OHA}$ respectively. The dispersion of magnetic nanoparticles helped in improving the mechanical properties of synthesized IPN. These types of hydrogels can be used in magnetic resonance imagining and tumor treatment. ${ }^{[56]}$

\section{Sulfonation}

When alginate is sulfated, it shows high blood compatibility because of structural similarity with heparin. Alban reported the synthesis of alginates by reaction of sodium alginates with $\mathrm{CLSO}_{3} \mathrm{H}$ in foramide. ${ }^{[57]}$ The procedure used for sulfated alginates synthesis comprises $10 \mathrm{~g}$ of sodium alginate mixed with sulfated reagent containing $20 \mathrm{mLCLSO} 3$ H and $80 \mathrm{~mL}$ formamide. A brown solution is obtained by preserving the mixture at $60^{\circ} \mathrm{C}$ for $3 \mathrm{~h}$ than the solution is precipitated by adding $200 \mathrm{~mL}$ of acetone. Furthermore 0.1 $\mathrm{mol} / \mathrm{L} \mathrm{NaOH}$ is added to adjust the $\mathrm{pH}$ of redissolved precipitate up to 10-11. The solution is dialyzed for $72 \mathrm{~h}$ and further concentrated to obtain alginate sulfate.

\section{Polysaccharides in drug delivery}

Polysaccharides possess several qualities that make them advantageous in the drug delivery scene. They are easily processed, offering a somehow low-cost biomaterial. They have excellent biocompatibility and biodegradability, and they can be easily used for targeted drug delivery through chemical modifications. For these reasons, many polysaccharides were used as vectors for the delivery of both small molecules and biologics.

\section{Chitosan}

Chitosan [ $\beta$-(1-4)-2-amino-2-deoxy-D-glucose] (CS) a deacetylated form of chitin is a naturally occurring linear biocompatible polysaccharide and is made up of $\mathrm{N}$-acetyl-D-glucosamine and D-glucosamine units. ${ }^{[58]}$ It is an innocuous, biodegradable, non-allergic, mucoadhesive and easily absorbable polymer. ${ }^{[3]}$ The mucoadhesive properties of chitosan makes it a promising candidate in the formulation of drug delivery systems. In a recent study, mucoadhesive chitosan nanoparticles were prepared by ionotropic gelation as a vector for the chemotherapeutic agent oxaliplatin. Ex-vivo studies showed that the use of chitosan increases 3-fold the drug penetration through oral mucosa. In addition, the number ofapoptotic cells increased in the presence of chitosan nanoparticles. ${ }^{[59]}$ Another study shows the development of chitosan nanoparticles through ionic gelation by electrostatic interaction between chitosan and 
carboymethyl-chitosan. Loaded with doxorubicin hydrochloride as an anticancer agent for colorectal cancer, these particles showed and Improved local drug concentration due to enhanced adhesion to intestinal mucosa, and a great reduction in cell viability. ${ }^{[60]}$

Several studies have shown the colon specificity of chitosan, but its intestinal absorption is limited by its degradation in alkaline media. ${ }^{[3,61-66]}$ Therefore, polyelectrolyte complexes of CS with water-soluble polyionic species were developed such as chitosan-pectin (CS-pectin) and chitosan sodium alginate (CS$\mathrm{NaAlg}$ ) that are easily swollen in neutral $\mathrm{pH} .{ }^{[3]} \mathrm{CS}-\mathrm{NaAlg}$ NPs produced by ionotropic gelation method have shown $81 \%$ insulin association efficiency. ${ }^{[3]}$ In both acidic and basic media, a swellable delivery system is produced by cross linking of CS with polyethylene glycol. ${ }^{[3]}$ The $\mathrm{pH}$ sensitive CS-Eudragit L10055 NPs produced by coacervation technique was beneficial for transport of insulin through gut mucosa. More recently, the slow dissociation rate of chitosan in cytoplasm was overcomed buy forming a polyelectrolyte complex of chitosan and carboxymethyl dextran. This system was used as a vector for micro RNA-145. The study shows a great efficacy of the system for gene transfection in-vitro. ${ }^{[67]}$

\section{Dextran}

Dextran (DEX) is a complex polysaccharide consisting of $\alpha$-1, 6 -linked D-glucopyranose with some degree of 1, 3-branching. Being hydrophilic, it can be effectively used in hydrogel-based carrier systems. ${ }^{[3,68,69]}$

Dextran is extensively used in pharmaceutical field for the delivery of therapeutics as reported in many studies. In last few years, using biotechnological strategies for different types of bioactive proteins and peptides to resolve the issue of their low oral bioavailability, they are administered parenterally. Due to its rapid elimination from circulation, repeated administration is required, to achieve optimum therapeutic effects. For this reason, new systems for prolonged delivery of proteins are needed to be investigated. One approach was proposed by introducing reactive double bonds by functionalizing the polymer with glycidyl acrylate. ${ }^{[2,69]}$ Dextran formed crosslink gels after exposure to $\gamma$-irradiations and this network was used for delivery of model protein invertase by loading into hydrogel. Moreover, by using this modification technique slow release is observed by increasing the cross-linked units. Furthermore, experiments showed that, degradation in presence of dextranase controlled the release pattern. Inside network diffusion of invertase is limited; the pore size gradually increases as chains are cleaved by dextranase resulting in the release of large amount of invertase.

Microcapsules of thermo-responsive poly ( $\mathrm{N}$-isopropylacrylamide) were synthesized for controlled release of stromal cell-derived factor (SDF)-1 $\alpha .^{[3,70]}$ Interconnected porous glycidyl methacrylated dextran microcapsules were prepared by double-phase emulsified condensation polymerization. In vitro studies revealed that these microcapsules showed thermo-responsive release of drug upon temperature variation. When implanted subcutaneously, these microcapsules exhibited sustained release of SDF-1 $\alpha$.

By mixing the oppositely charged cross-linked dextran microspheres, a self-gelling hydrogel system is obtained. ${ }^{[2,71]}$ These physical gels have various advantages over chemical ones. Crosslinking agents used in chemical cross-linking are often toxic leading to loss of activity of the entrapped substance, and require removal before the delivery. Physical gels, on the other hand, have ability to form gels in situ; so, can be administered by injection as liquid formulations.

For nasal drug delivery systems, dextran microspheres have also been tested. ${ }^{[2]}$ In animal models, low molecular weight drugs, peptides and proteins showed improved bioavailability due to increased residence time of drug as compared to solutions and no unwanted effect of mucosal immune response 
has been observed. Dextran polymers have also been reported for colon drug delivery ${ }^{[2]}$. Some researchers have studied the in vitro stability of dextran hydrogels and reported them as appropriate matrices for colonic delivery of specific drugs. Indeed, colonic specific delivery systems are of great interest for localizing treatment. The hydrogel obtained by cross-linking reaction between different amount of hexamethylene isocyanate and dextran samples and by incubating those with human small intestine enzymes were studied (Amyloglucisidase, invertase and pancreatin). The obtained results showed stable hydrogels entirely degraded in a human colonic fermentation model.

\section{Hyaluronic acid}

Hyaluronic acid is an unbranched unsulfated glycosamino-glycane contains repeating disaccharides units of $\mathrm{D}$ - glucuronic acid and $\mathrm{N}$-acetylglucosamine linked $\alpha-(1 \rightarrow 4)$ and $\beta-(1 \rightarrow 3)$ respectively. ${ }^{[72]}$ It is considered as a major constituent of synovial fluid and found in cartilage, where its function is to lubricate the body tissues and prevent spreading of invading microorganisms. There is no commercially available delivery product using hyaluronic acid (HA) except decalage, therefore, there is greater potential to develop physical or chemical cross-linked hydrogel depot systems. ${ }^{[3]}$ Microparticles formulation prepared by solvent evaporation and spray drying method. Using Hyaff11p50, in which $50 \%$ of carboxyl groups of HA are esterified with benzoyl alcohol and release of hGH (Human Growth Hormone) showed within 7day. ${ }^{[3,73]}$ Another formulation which showed improved patient compliance, is prepared by spray drying technique using hGH/HA/lecithin. ${ }^{[3,74]}$ Encapsulating the protein and peptides, in a novel hyaluronic-based nanogel showed controlled release profile without affecting the chemical stability. ${ }^{[3,75]}$ For delivery of peptides, hybridized nanoparticles were produced by gelating HA and ferric oxide. In another approach for proteins delivery, cyclodextrin is coupled with porous microparticles of hyaluronic acid complex with lysozyme, showed improved EE. ${ }^{[3]}$

More recently, to increase the chemotherapeutic efficacy of doxorubicin-loaded liposomes against osteosarcoma. The liposomes were decorated with HA as a ligand to CD44 to increase targetability. Indeed, in-vitro studies showed that the HA coated liposomes have a higher cytotoxicity to osteosarcoma cells. Moreover, these due to HA non-covalent coating, these liposomes found to have a preference in internalizing to osteosarcoma cells over human liver cells. ${ }^{[76]}$ The CD44 targeting ability was also exploited elsewhere in the synthesis of $\mathrm{HA}$-based $\mathrm{pH}$-sensitive polymer-modified liposomes. ${ }^{[77]}$

\section{Sodium Alginate}

Sodium Alginate ( $\mathrm{NaAlg}$ ), another interesting polysaccharide is used in the pharmaceutical field because of its gelling properties in aqueous media. ${ }^{[78]} \mathrm{NaAlg}$ is an unbranched polysaccharide consisting of 1$4^{\prime}$ linked $\beta$-D-mannuronic acid (M) and $\alpha$-L-guluronic acid (G) moieties in different compositions. ${ }^{[3,79]}$ It has ability to form hydrogels by addition of metal ions to its aqueous media. NaAlg-based hydrogels simultaneously release growth factors therefore, widely used in tissue regeneration. ${ }^{[3,80,81]}$ NaAlg-based NPs prepared by solvent diffusion, spray drying, and ionic crosslinking with electro-hydrodynamic spraying methods for delivery of insulin, have shown better entrapment efficiency values from 38 to $90 \% \cdot{ }^{[3,82,83]} \mathrm{pH}$ dependent controlled release properties of sodium alginate protects the integrity of insulin unless in the presence of very high temperature during spray drying. ${ }^{[3,84]}$ For delivery of connexin-43 carboxyl-terminus mimetic peptides to wound site, NaAlg-based microcapsules with Polly-L-ornithine were used. Mahidhara et al. developed CS-NaAlg coated NPs loaded with lactoferrin, (natural milk-based protein) a multifunctional anti-cancer drug, to improve its intestinal absorption. ${ }^{[85]}$ 


\section{Xanthan}

Xanthan has cellulosic backbone of D-glucose linked $\beta-1,4$, and every alternate glucose side chain consists of $\beta$-D-mannose-(1,4) - $\beta$-D glucuronic acid-(1,2)- $\alpha$-D-mannose. ${ }^{[86]}$ Xanthenes have been widely used as tablet excipient but its use for controlled release of therapeutics has not been much reported. Therefore, it has been widely studied by researchers and they reported one interesting application, as xanthan (polyanion) forms macromolecular complexes with chitosan (polycations). ${ }^{[2,87]}$ Gels obtained by this process are homogenous porous systems with a fibrillar structure and channels formed by fibrillar gels allow the entry of polymeric substrates to immobilized enzymes. The advantage of polyionic hydrogels is that they stabilize proteins by creating ionic microsystems. Besides this, the porous structure also facilitates the diffusion of substrates and product of enzymatic reaction. This property reveals that they can be used safely in pharmaceutical formulations for loading of bioactive substances. Xanthan has also been utilized in preparation of sponge-like in-situ gelling inserts for delivery of peptides and proteins in the nasal cavity. ${ }^{[2,88]}$ By using xanthan and other polymers e.g., carrageenan, water uptake governs the drug release, and a complex network is formed due to electrostatic interaction and osmotic forces between polymer and drug. The major problem with nasal drug delivery is the mucocilliary clearance; nasal residence time of drug can be increased by using bio adhesive polymers. Therefore, drug is embedded into highly porous polymeric sponges. After compression, recovery of a sponge-like structure is more efficient with xanthenes as compared to carrageenan and alginate. It displays better elasticity as compared to other polymers, alginate inserts dissolved rapidly exhibited poor bio adhesion and delayed drug release. In contrast, xanthan and carrageenan gelled without loss of any mass and provide extended drug release over several hours. These properties of xanthan and carrageenan make them promising candidates for bio adhesives nasal inserts.

\section{Polysaccharides in Endocrinology}

\section{Importance of polysaccharides in the cellular and biological systems}

Polysaccharide molecules are high-molecular-weight carbohydrates, they are sugar polymers formed from monosaccharides. ${ }^{[89]}$ Polysaccharides differ in size and their structure varies from a simple linear to a highly branched complex form. ${ }^{[00]}$ The level of polymerization differs according to the type of polysaccharide and can varies from 7,000 - 90,000 units as in cellulose and amylopectin respectively. ${ }^{\text {[89] }}$ Polysaccharides could be categorized as homopolysaccharides which comprise only one kind of sugar's residue such as starch or as heteropolysaccharides which are formed of two or more diverse types of residues of the sugar such as arabinoxylans and hyaluronic acid. Polysaccharides can be represented as heparin, a sulfated polysaccharide, aids in blood coagulation, while hyaluronan plays a lubricating role in human joints. Also located in cell walls, the surface polysaccharides contribute to cell recognition, adhesion, cell growth regulation, and in cancer metastasis and inflammation. ${ }^{[91]}$ By studying the characteristics of polysaccharides, we came to the point of their abundant importance in the field of pharmaceutics. Their chemistry helps in determining their role in normal physiology of our body, and when we talk about the endocrine system especially their activity, it is very eye catching. They strongly showed their impact on the regulation of the hormones and glands. ${ }^{[92]}$ All naturally present polysaccharides have mimicking part in normal underlying mechanism of our glands so they helped out to treat their ailments. They worked on different receptors as well to regulate the synthesis and activation of different hormones. Like Hyaluronic acid is mostly present in colon tissue; verification suggests that hyaluronic acid theater is an important part in treating colon disorders like inflammatory bowel disorder, ulcerative colitis. Rudzki et al. reported hyaluronan receptor CD44 are strongly over expressed in tumors 
compared to colon. ${ }^{[93]}$ Polysaccharides relieve many system disorders and disfunction and protect them against stress and agents-induced impairment particularly endocrine system as explained below.

\section{Relations between Endocrine glands and Polysaccharides}

Polysaccharides are influenced by several hormones; their turnover is modulated by the endocrine secretions. The status of the endocrine gland's activity is a key factor in polysaccharides synthesis. Additionally, polysaccharides play roles in hormonal functions. ${ }^{[94]}$ In connective tissues, hormones modify the turnover of polysaccharides. In animals that have pituitary gland removed (hypophysectomized), a decrease in chondroitin sulphate and hyaluronic acid was noticed, when given growth hormones, these animals were found to have enhanced chondroitin sulfate turnover, while hyaluronic acid was not affected. The extraction of the parathyroid was found to increase the catabolization of chondroitin sulphate in some connective tissues, while in some tissues its' synthesis maybe stimulated. In hypothyroid animals, polysaccharides synthesis was found to be decreased and was altered by thyroxine. Estradiol inhibits the synthesis of chondroitin sulphate in cartilage and aorta, while cortisone inhibits chondroitin sulphate and hyaluronic acid. ${ }^{[95]}$ The effect of the polysaccharide-rich extract of Phragmites rhizoma (PEP) was studied versus restraint on water inundation (RWI) forced swimming-induced stress. Exposure to RWI stress elevated the ulcer index, bleeding, the mass of the spleen and adrenal gland, circulating glucose levels, cortisol, total cholesterol, and creatine kinase. RWI stress upregulated Myeloperoxidase and thiobarbituric acid-reactive substance clearly. The antioxidants such as glutathione, glutathione peroxidase, and superoxide dismutase were reduced in the stomach. These RWI stress induced-changes were successfully recovered by pretreatment with PEP. Treating with PEP protected body weight from losing, extended capacity of mice to swim and lowered creatine kinase plasma concentrations significantly, as muscle fatigue biomarker. These anti-stress and anti-fatigue effects of PEP are mediated by suppressing the hyperactivity of the hypothalamus-pituitary-adrenal axis, and antagonistic effect. ${ }^{\text {[96] }}$

\section{On pituitary}

Pituitary gland polysaccharides have been found to be related with gonadotropic functions. ${ }^{[94]}$ Piromen $^{\circledR}$, a bacterial polysaccharide complex, has been found to improve a variety of diseases, stimulates the pituitary gland, in cases of adrenal disfunction, to release the adrenal corticotropic hormone. ${ }^{\text {[97] }}$ Polysaccharides were listed among different active constituents recognized as antidepressant agents categorized into saponins, flavonoids, and alkaloids. In addition, polysaccharides exert their effects and classified based on their mechanisms such as elevating synaptic levels of monoamines, relieving the disorder of the hypothalamic-pituitary-adrenal axis, reducing the injury of neuroplasticity, struggling to immunity dysregulation. ${ }^{[98]}$ In mice, Vitexin relieves streptozotocin-induced diabetes and its complication were sexual abnormality and fertility destructions, this alleviating effect was through a mechanism on the hypothalamus-pituitary-gonadal axis. ${ }^{[99]}$ Polysaccharide reduces factors induced-fatigue through the hypothalamus-pituitary-adrenal axis. ${ }^{[96]}$ Table 1 shows some effects of polysaccharides on pituitary gland.

\section{On thyroid}

Ganoderma lucidum polysaccharides were tested on mice models with graves' disease, to study their effect on hyperthyroidism and the accompanied liver injury. It was found that these polysaccharides improved the liver injury caused by hyperthyroidism but were not able to be effective on the disease itself. ${ }^{[100]}$ The effect of Cyclocarya paliurus polysaccharide (CPP) was also tested on cell apoptosis in thyroid cancer cells and was found to suppress activation of $\mathrm{p}-\mathrm{Akt}, \mathrm{Akt}$, and $\mathrm{Bcl}-2$, enhancing thyroid cancer cell apoptosis, while activating Bax, allowing CPP to be used as a thyroid cancer treatment. ${ }^{[101]}$ In clinical trial 
study, the gel of an autocross linked polysaccharide appeared efficient and safe to be used in avoiding adhesions in patients after thyroidectomy. ${ }^{[102]}$

\section{On parathyroid and bone}

Polysaccharide pneumococcal vaccine was used to activate B cells directly without interacting with Tlymphocytes leading to effective immunity.[103] Parathyroid hormone (PTH) analog (teriparatide) has been used in osteoporosis management. PTH receptors have been found on most immunologic cells since the 1980s, these receptors could be activated by polysaccharide pneumococcal vaccine. The roles of PTH were evaluated as immunomodulators, although parathyroidectomy has been found to alter the immunologic defect in patients with elevated PTH levels. As B lymphocytes identification of polysaccharide antigens is a T-cell autonomous communication. Using polysaccharide antigens in the pneumococcal vaccine was adequate and indicates that the weakness in producing antibodies was more due to interaction of T-cell-B-cell.[104] In a study on diabetic induced rats, it was found that the polysaccharide Yunzhi, (also known as Trametes versicolor (L.:Fr.) Pilát or TVP) demonstrated a protective effect on bone properties, through the improved control of hyperglycemia.[105] Age related tissue damage and endocrine diseases, such as osteoporosis, are induced by an increase in oxidative stress and the lack of antioxidant defenses. An ingredient from a traditional Chinese medicine, known as Dendrobium officinale polysaccharides has been found to be a potential therapy for age related osteoporosis, through its ability to attenuate bone loss and marrow adipose tissue accumulation by NRF2 antioxidant signaling [106]. Table 1 shows some effects of polysaccharides on thyroid and parathyroid glands.

\section{On adrenal gland}

Polysaccharides derived from Klebsiella pneumoniae were labelled with C14, and injected in four animals' types, guinea pigs, mice, rabbits and rats. It was found that all animals had the same tissue distributions of C14, with the exception of the adrenal cortex where the highest concentration was found in one animal, the guinea pig. ${ }^{[107]}$ It was also found that cortisol in low concentrations was able to affect the growth of embryonic chick's cartilaginous limb-bone rudiments. This may be possible as cortisol was found to aid in the synthesis of polysaccharides in cell matrix. ${ }^{[108]}$ In the rat adrenal gland (in vitro) the biosynthesis of aldosterone and 18-oxycorticosterone was reduced by 40 to $55 \%$ when rats were repeatedly administered with carboxymethylchitin and chondroitin sulfate in doses of 20 and $120 \mathrm{mg} / \mathrm{kg} / 24$ hours. While carboxymethylcellulose, algin and hyaluronic acid were not affected. ${ }^{[109]}$ High ambient temperatures were seen to affect rats through a noticeable increase in plasma concentrations of epinephrine, cortisol, hypothalamic corticotropin-releasing hormone and heat-shock protein 70 (HSP70), while Lycium barbarum polysaccharide was found to increase plasma levels of HSP70 and the mRNA expression of neuropeptide $Y$ (NPY) to insure body protection from increased temperatures and damage by heat stress. ${ }^{[110]}$ A study was carried out on twenty-four healthy and normal fetuses of non-descript goat to identify the locations of polysaccharides and acid mucopolysaccharides in adrenal glands throughout prenatal in different gestation stages (0-50 days, 51-100 days and 101-delivery). In connective tissue, it was noticed that extreme of periodic acid Schiff (PAS) reaction was increasing in the capsule of adrenal gland with the age progress. The cytoplasm of fetal and complete cortical cells ranged between modest to weakness PAS reaction. While cytoplasm of the cells in adrenal medulla demonstrated modest PAS reaction. But connective capsule exhibited extreme to moderate reaction for acid mucopolysaccharides (AMPS). The cell cytoplasm of fetal and definitive in the adrenal cortex presented anemic reaction for AMPS, then enhanced to extreme reaction in the later ages. Medulla cells exhibited AMPS's modest to 
extreme reaction in its cytoplasm while less reaction was shown after 130 days ahead. Severe AMPS reaction was seen in cytoplasm, sinusoids wall, and trabeculae of deteriorating cells. ${ }^{[111]}$ Polysaccharide relieves factors induced-stress through the hypothalamus-pituitary-adrenal axis. ${ }^{[105]}$ Table 1 shows some effects of polysaccharides on adrenal glands.

\section{On pancreas, diabetes, and glucose metabolism}

Diabetes mellitus is a common endocrine metabolic disorder causing many health complications. Diabetic drugs have definite side effects endangering the lives of patients. Dietary polysaccharides, on the other hand, have been found to possess anti-diabetic potential, derived from natural sources, such as medicinal plants and foods, edible mushrooms, grains, fruits and vegetables. ${ }^{[12]}$ Most chemical originated drugs have side effects and are unable to prevent the progression of diabetic complications. Recently several herbal medications have been used to prevent diabetic complications due to their relative safety. ${ }^{[113]}$ Evaluation of dietary polysaccharides were found to have hypoglycemic, hypolipidemic, antioxidant, and anti-inflammatory effects leading to the enhancement of $\beta$-cells and reducing $\beta$-cell dysfunction. They were also able to influence insulin receptors enhancing insulin signaling pathways (PI3K/Akt, ERK/JNK/MAPK). ${ }^{[112]}$ Polysaccharides derived from mushrooms have been specifically found to positively impact diabetic complications. ${ }^{[113]}$

\section{On gonads (Ovary \& Testes)}

A study on ameliorating the toxicity effects of cyclophosphamide (CP) in mice ovaries, using polysaccharide from Sepia esculenta ink (SEP) reported that SEP was able to reverse the negative effects of CP, ovarian failure, by inhibiting p38 MAPK signaling pathway in addition to activating the PI3K/Akt signaling pathway. ${ }^{[114]}$ Another study was conducted on naturally aging mice with premature ovarian failure, the effects of polysaccharides from Dendrobium officinal (DOP) was found to inhibit the nuclear factor $-\mathrm{kB}$ (NF-kB) and $\mathrm{p} 53 / \mathrm{Bcl}-2$-mediate signaling pathways, reducing damage caused by aging. In addition to increasing mitochondrial numbers and improving its membranes, also the number of different follicular cell stages was noticed to increase. ${ }^{[115]} \mathrm{An}$ increase in follicles and corpus luteum was noticed to improve in aging mice by polysaccharides of Fructus corni. ${ }^{[116]}$ A potential therapeutic agent for the treatment of ovarian cancer was studied, B. polyandra polysaccharides, a traditional herbal medicine, was found to trigger apoptosis and inhibit migration and invasion of ovarian cancer cells, in addition to the induction of cell cycle arrest at S phase. ${ }^{[117]}$ Astragalus polysaccharide, a naturally accruing antioxidant, was found to arrest ovarian cancer cell growth through the axis of miR-27a/FBXW7 in vitro, confirming the possible therapeutic activity of Astragalus polysaccharide as an ovarian cancer treatment. ${ }^{[118]} \mathrm{A}$ wellknown Chinese medical herb, Lycium barbarum is used as a remedy for male infertility. Lycium barbarum polysaccharide (LBP) is the most important functional part of the fruit. It was found that LBP protects against damage induced by heat exposure in rat testis, in addition to raising levels of sex hormones in the damages tissue. A dose dependent protective effect of LBP was seen in mice testicular cells induced by $\mathrm{H} 2 \mathrm{O} 2$, where cells were protected against DNA oxidative damage. ${ }^{[119]}$ A secondary complication of diabetes is spermatogenic dysfunction, (LBP) has protective effects on spermatogenic dysfunction through increasing activities of antioxidant enzymes, and inhibiting cell apoptosis in addition to regulating expression of SIRT1/HIF-1 $\alpha$ in testicular cells. ${ }^{[120,121]}$ Cyclophosphamide (CP) has been used as an antitumor drug, and has been known to cause reproductive damage, through induced oxidative stress in the testes. Squid ink polysaccharides was found to significantly ameliorate and offer protective effects against $\mathrm{CP}$, including sexual hormone contents, marker enzymes activities, testicular antioxidant ability and histopathological features. ${ }^{[122]}$ Table 1 shows some effects of polysaccharides on gonadal glands. 


\section{Polysaccharides in vaccines}

The use of polysaccharide in vaccines development was dated to the 1945 where a capsular polysaccharide vaccine against Streptococcus pneumoniae was made. After that, the focus was made on bacteria killing vaccines especially after the increase in bacterial antibiotic resistance and meningitis epidemics. ${ }^{[123,124]}$ Polysaccharides are naturally produced as part of bacteria cell wall. They serve as the first line of defense against complements and bacteriophages. Therefore, building a bacteria-fighting vaccine base on polysaccharide capsule is common sense. In fact, several polysaccharide-based vaccines are already commercialized. To cite a few, Pneumovaxll, Ac Vax, and Typhim Vi were developed against Streptococcus pneumoniae, Neiseria meningitidis, and Salmonella typhi respectively. ${ }^{[125-127]}$ Plain or conjugated polysaccharides were introduced in formation of different vaccines.

\section{Plain polysaccharide}

The polysaccharide capsules of bacteria are an important determinant of virulence. These capsules facilitated the adherence of bacteria to biological surfaces. In addition, they cloak the bacteria from antibodies recognition, complement adherence, and phagocytosis. However, the capsules themselves are not toxic and can induce the production of polysaccharide specific antibodies that can last for several years. All the mentioned characteristics attracted the development of polysaccharide-based vaccines as a response to bacterial resistance against antibodies. ${ }^{[128,129]}$

Table 1 Effect of some polysaccharide on different glands

\begin{tabular}{|c|c|c|}
\hline Gland & Effect & Ref \\
\hline $\begin{array}{l}\text { Pituitary } \\
\text { gland }\end{array}$ & $\begin{array}{l}\text { Polysaccharides are linked to } \\
\text { gonadotropic functions controlled by } \\
\text { pituitary hormones. } \\
\text { Piromen }{ }^{\circledR} \text { (a bacterial polysaccharide } \\
\text { complex): stimulates pituitary gland. }\end{array}$ & {$[944],[97]$} \\
\hline Thyroid & $\begin{array}{l}\text { Cyclocaraya paliurus polysaccharide } \\
\text { (CPP): increase thyroid cancer cell } \\
\text { apoptosis. }\end{array}$ & [101] \\
\hline Parathyroid & $\begin{array}{l}\text { Trametes versicolor (L.:Fr) Pilat (TVP) } \\
\text { has protective effect on bone in } \\
\text { diabetic rats. } \\
\text { Polysaccharide pneumococcal } \\
\text { vaccine activates B cells. } \\
\text { Dendrobium officinale } \\
\text { polysaccharide is a potential therapy } \\
\text { for age related osteoporosis }\end{array}$ & $\begin{array}{l}{[104],[105],} \\
{[106]}\end{array}$ \\
\hline
\end{tabular}




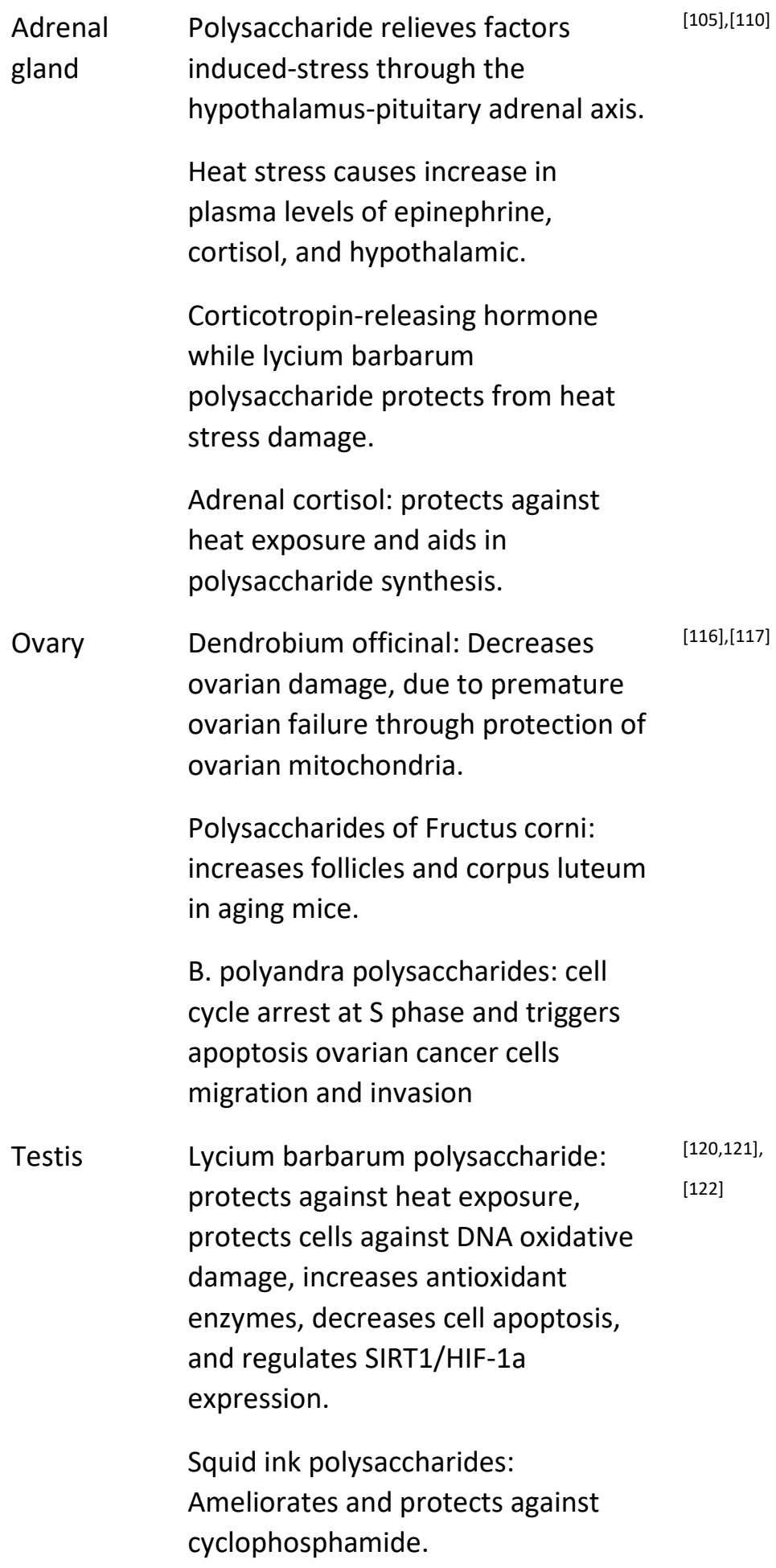

Several vaccines were developed based on the polysaccharide capsules, such as vaccines against Neisseria meningitidis, Streptococcus pneumoniae, and Haemophilus influenzae type b. ${ }^{[130]}$ One of the simplest capsular polysaccharide vaccine is used against typhoid, and contains uniquely the Vi polysaccharide antigen ( $\alpha$-D-(1-4)-linked $\mathrm{N}$-acetylgalactosaminuronate) with lactose as a stabilizer. It offers $70 \%$ efficacy against typhoid fever with far less severe side effects comparing with whole cell typhoid vaccines. ${ }^{[131]}$ The 
first FDA approved pneumococcal polysaccharide vaccine in 1983 contained 23 serotype-specific polysaccharides and protects against $90 \%$ of capsular serotypes. A more recent approved formulation contains only 13 different serotypes. ${ }^{[132]}$

Despite the importance of capsular polysaccharide vaccines especially in the protection of the elderly against life-threatening diseases, some limitations can be observed. Plain polysaccharide are poorly immunogenic, this will prevent the development of immunological memory. ${ }^{[133]}$ In the case of meningococcal vaccines, several trials in several countries reported a low impact on bacteria carriage in immunized individuals. Bacteria can stay for months inside an asymptomatic infectious host. Thus, it was found that this kind of vaccine is inefficient in treating children under 2 years of age, because they are more susceptible to infections. For these reasons, a novel approach was needed to obtain a more efficient polysaccharide-based vaccine formulation.

\section{Conjugated polysaccharide}

The main problem of polysaccharide-based vaccines is the low immunogenicity which leads to the limitation discussed above. To overcome this problem, polysaccharides can be conjugated to immunogenic protein carrier as part of the vaccine formulation. In fact, polysaccharides are usually found in nature in a conjugated form either with lipids or proteins to form glycolipids and glycoproteins respectively with the role of cell recognition in bacteria and other infections. ${ }^{[134]}$

Several studies were conducted in the last four decades that can prove the efficacy of a conjugated polysaccharide in vaccine development. in the fight against Haemophilus influenzae type b (Hib), four different conjugated vaccines were developed with polyribosylribitol phosphate of the outermost layer of $\mathrm{Hib}$ as a capsular polysaccharide. A combination with other vaccines were also developed such as Diphtheria toxoid conjugate, tetanus toxoid conjugate, and meningococcal outer membrane protein conjugate. Several studies show that these vaccines provide an above $90 \%$ efficacy in babies from the first month of their lives. Comparing to non-conjugated vaccines, that are efficient with children between 18 and 37 months but not with younger children, this was considered as a breakthrough. ${ }^{[135]}$ Same pattern was observed between Pneumococcal conjugated and non- conjugated polysaccharide-based vaccine. The immunogenicity was increased after conjugation of a protein carrier alters the immune response to become T-cell dependant, while plain polysaccharide induces a T-cell independent response which is generally weaker. ${ }^{[136]}$

The immunogenicity of conjugated polysaccharide vaccine is related to multiple factors. The type of protein carrier and the included adjuvants are obviously significant. However, factors related to the polysaccharide part of the vaccines also exist. For instance, Arcuri et al. studied the effect of the Vi polysaccharide length on the immune response in mice against Salmonella enterica Typhi infections. It was found that the length of the Vi chain has a direct impact on the anti-Vi IgG secretion. Full length Vi induces a peak response of IgG at first immunization without enhancing the magnitude of the response at second dose. While fragmented Vi gives a lower response at first immunization but a similar response to the one induced by full length $\mathrm{Vi}$ at second dose. ${ }^{[137]}$ In addition, polysaccharides are generally more immunogenic that oligosaccharides in pneumococcal conjugated vaccines. ${ }^{[138]}$

\section{Conclusions}

Polysaccharides show versatility, as pointed through this review, due to complex structure and derivatization further increases their possible uses. Moreover, their biodegradable character added 
costiveness towards their use in pharmaceutical field as they deliver drug at their specific site. Their possible use in endocrinology made them a more attractive tool in formation and activation of different hormones and glands. This overview on polysaccharides clearly shows ever-increasing number of research works from all over the world. They are leading to the stimulation and characterization of different varieties of hormones with distinctive properties that make them appropriate candidate for applications in the endocrine systems. Hyaluronic acid and chondroitin sulphate are naturally present substances in our bodies and helped many glands to perform their activities effectively. Many polysaccharides enhanced the working abilities of different hormones released from pituitary, thyroid, adrenal and gonads. They induced special properties in their functions, activation and formation of their appropriate hormones and prompt their leading mechanisms. Successfully by introducing polysaccharides in endocrine systems related problems, beneficial effects were gained. We can treat many diseases related to sex hormones, bones dysfunctions, thyroid and parathyroid abnormalities. Polysaccharides-based vaccines are attractive tools for bacterial infections and stress damaged conditions.

Keywords: Natural Polysaccharides • membranes/films • functionalization • polysaccharides in Endocrinology • polysaccharides in Vaccines

[1] G. Levourch, N. Lebaz, A. Elaissari, Polymers 2020, 12, 1413.

[2] T. Coviello, P. Matricardi, C. Marianecci, F. Alhaique, Journal of Controlled Release 2007, 119, 524.

[3] K. Ganguly, K. Chaturvedi, U. A. More, M. N. Nadagouda, T. M. Aminabhavi, Journal of Controlled Release 2014, 193, 162-173.

[4] L. Ma, H. Chen, Y. Zhang, N. Zhang, L. Fu, Carbohydrate Polymers 2012, 89, 371-378.

[5] C. Brasselet, G. Pierre, P. Dubessay, M. Dols-Lafargue, J. Coulon, J. Maupeu, A. Vallet-Courbin, H. de Baynast, T. Doco, P. Michaud, C. Delattre, Applied Sciences 2019, 9, 1321.

[6] C. Yu, X. Kecen, Q. Xiaosai, in Biopolymer Grafting: Synthesis and Properties, Elsevier, 2018, pp. 295-364.

[7] R. Kosheleva, A. C. Mitropoulos, G. Z. Kyzas, in Composite Nanoadsorbents, Elsevier, 2019, pp. 49-66.

[8] T. Sun, P. Xu, Q. Liu, J. Xue, W. Xie, European Polymer Journal 2003, 39, 189-192.

[9] W. Xie, Carbohydrate Polymers 2002, 50, 35-40.

[10] T. Sun, W. Xie, P. Xu, Carbohydrate Polymers 2004, 58, 379-382.

[11] P. Qu, G.-F. Wu, J.-X. Wu, Y.-F. Zhao, Nuclear Science and Techniques 2017, 28, DOI 10.1007/s41365-017-0312-x.

[12] E. A. El-Hefian, M. M. Nasef, A. H. Yahaya, E-Journal of Chemistry 2010, 7, S349-S357.

[13] C. N. Cheaburu-Yilmaz, S. Y. Karavana, O. Yilmaz, Current Organic Synthesis 2017, 14, 785-797.

[14] E. Bosquez-Molina, L. Zavaleta-Avejar, in Chitosan in the Preservation of Agricultural Commodities, Elsevier, 2016, pp. 33-64.

[15] Y. Liu, B. Zhang, V. Javvaji, E. Kim, M. E. Lee, S. R. Raghavan, Q. Wang, G. F. Payne, Biochemical Engineering Journal 2014, 89, 21-27.

[16] A. Aljawish, I. Chevalot, J. Jasniewski, J. Scher, L. Muniglia, Journal of Molecular Catalysis B: Enzymatic 2015, 112, 25-39.

[17] A. Celli, M. W. Sabaa, A. N. Jyothi, S. Kalia, in Polymeric Hydrogels as Smart Biomaterials, Springer International Publishing, 2015, pp. 189-234. 
[18] D. L. Hall, "Application of Immobilized Amphiphilic (Hybrid) Molecular Brushes for Surface Control and Dynamic Response - ProQuest," can be found under https://search.proquest.com/openview/903c5e492b5d8231c0a469cf2572e982/1?cbl=18750\&diss=y\&p q-origsite=gscholar, 2014.

[19] J. Á. Montes, A. Ortega, G. Burillo, Journal of Radioanalytical and Nuclear Chemistry 2014, DOI 10.1007/s10967-014-3805-7.

[20] Z. Li, L. Wang, Y.-H. Ma, W.-T. Yang, Chinese Chemical Letters 2015, 26, 1351-1354.

[21] R. W. Jeanloz, E. Forchielli, Journal of Biological Chemistry 1950, 186, 495-511.

[22] K. Hirano, S. Sakai, T. Ishikawa, F. Y. Avci, R. J. Linhardt, T. Toida, Carbohydrate Research 2005, 340, 2297-2304.

[23] A. Borzacchiello, L. Russo, S. Zaccaria, L. Ambrosio, in Polysaccharide Hydrogels, Pan Stanford, 2015, pp. 417-447.

[24] S. Pelletier, P. Hubert, F. Lapicque, E. Payan, E. Dellacherie, Carbohydrate Polymers 2000, 43, 343-349.

[25] K. Tommeraas, C. Eenschooten, Aryl/Alkyl Succinic Anhydride-Hyaluronan Derivatives, 2009.

[26] C. Eenschooten, F. Guillaumie, G. M. Kontogeorgis, E. H. Stenby, K. Schwach-Abdellaoui, Carbohydrate Polymers 2010, 79, 597-605.

[27] L. Pravata, C. Braud, M. Boustta, A. E. Ghzaoui, K. Tømmeraas, F. Guillaumie, K. SchwachAbdellaoui, M. Vert, Biomacromolecules 2008, 9, 340-348.

[28] C. E. Schanté, G. Zuber, C. Herlin, T. F. Vandamme, Carbohydrate Polymers 2011, 85, 469-489.

[29] A. Fischer, M. C. Houzelle, P. Hubert, M. A. V. Axelos, C. Geoffroy-Chapotot, M. C. Carré, M. L. Viriot, E. Dellacherie, Langmuir 1998, 14, 4482-4488.

[30] M. Leonard, M. R. D. Boisseson, P. Hubert, F. Dalençon, E. Dellacherie, Journal of Controlled Release 2004, 98, 395-405.

[31] A. Sinquin, P. Hubert, E. Dellacherie, Langmuir 1993, 9, 3334-3337.

[32] L. Yang, B. Zhang, L. Wen, Q. Liang, L. Zhang, Carbohydrate Polymers 2007, 68, 218-225.

[33] E. Broderick, H. Lyons, T. Pembroke, H. Byrne, B. Murray, M. Hall, Journal of Colloid and Interface Science 2006, 298, 154-161.

[34] P. Bulpitt, D. Aeschlimann, Journal of Biomedical Materials Research 1999, 47, 152-169.

[35] E. J. Oh, K. Park, K. S. Kim, J. Kim, J.-A. Yang, J.-H. Kong, M. Y. Lee, A. S. Hoffman, S. K. Hahn, Journal of Controlled Release 2010, 141, 2-12.

[36] G. D. Prestwich, D. M. Marecak, J. F. Marecek, K. P. Vercruysse, M. R. Ziebell, Journal of Controlled Release 1998, 53, 93-103.

[37] K. P. Vercruysse, G. D. Prestwich, Critical ReviewsTM in Therapeutic Drug Carrier Systems 1998, $15,43$.

[38] I. Danishefsky, E. Siskovic, Carbohydrate Research 1971, 16, 199-205.

[39] N. Nakajima, Y. Ikada, Bioconjugate Chemistry 1995, 6, 123-130.

[40] C. B. Highley, G. D. Prestwich, J. A. Burdick, Current Opinion in Biotechnology 2016, 40, 35-40.

[41] N. Follain, S. Montanari, I. Jeacomine, S. Gambarelli, M. R. Vignon, Carbohydrate Polymers 2008, 74, 333-343.

[42] J. W. Kuo, D. A. Swann, G. D. Prestwich, Bioconjugate Chemistry 1991, 2, 232-241.

[43] T. Pouyani, G. D. Prestwich, Bioconjugate Chemistry 1994, 5, 339-347.

[44] C. Galant, A.-L. Kjøniksen, G. T. M. Nguyen, K. D. Knudsen, B. Nyström, The Journal of Physical Chemistry B 2006, 110, 190-195. 
[45] K. Abu-Rabeah, B. Polyak, R. E. Ionescu, S. Cosnier, R. S. Marks, Biomacromolecules 2005, 6, 3313-3318.

[46] C. G. Gomez, G. Chambat, A. Heyraud, M. Villar, R. Auzély-Velty, Polymer 2006, 47, 8509-8516.

[47] B. Polyak, S. Geresh, R. S. Marks, Biomacromolecules 2004, 5, 389-396.

[48] J. Yang, J. Zhao, Y. Fang, Carbohydrate Research 2008, 343, 719-725.

[49] H. Zhu, J. Ji, R. Lin, C. Gao, L. Feng, J. Shen, Biomaterials 2002, 23, 3141-3148.

[50] T. Boontheekul, H.-J. Kong, D. J. Mooney, Biomaterials 2005, 26, 2455-2465.

[51] H. J. Kong, D. Kaigler, K. Kim, D. J. Mooney, Biomacromolecules 2004, 5, 1720-1727.

[52] C. G. Gomez, M. Rinaudo, M. A. Villar, Carbohydrate Polymers 2007, 67, 296-304.

[53] A. H. Pandit, N. Mazumdar, S. Ahmad, Int J Biol Macromol 2019, 137, 853-869.

[54] F. Ullah, F. Javed, H. Md. Akil, in Nano Hydrogels: Physico-Chemical Properties and Recent Advances in Structural Designing (Eds.: J. Jose, S. Thomas, V.K. Thakur), Springer, Singapore, 2021, pp. 263-280.

[55] M. Kheirabadi, L. Shi, R. Bagheri, K. Kabiri, J. Hilborn, D. A. Ossipov, Biomater. Sci. 2015, 3, 14661474.

[56] S. Wang, J. Chi, Z. Jiang, H. Hu, C. Yang, W. Liu, B. Han, Carbohydrate Polymers 2021, 256, 117519.

[57] S. Alban, Carbohydrate Polymers 2002, 47, 267-276.

[58] N. M. Saidin, N. K. Anuar, M. M. M. Affandi, Journal of Applied Pharmaceutical Science 2018, 8, 141-157.

[59] B. N. Matos, M. N. Pereira, M. de O. Bravo, M. Cunha-Filho, F. Saldanha-Araújo, T. Gratieri, G. M. Gelfuso, International Journal of Biological Macromolecules 2020, 154, 1265-1275.

[60] C. Feng, J. Li, M. Kong, Y. Liu, X. J. Cheng, Y. Li, H. J. Park, X. G. Chen, Colloids and Surfaces B: Biointerfaces 2015, 128, 439-447.

[61] S. A. Agnihotri, N. N. Mallikarjuna, T. M. Aminabhavi, Journal of Controlled Release 2004, 100, 528.

[62] S. Al-Qadi, A. Grenha, D. Carrión-Recio, B. Seijo, C. Remuñán-López, Journal of Controlled Release 2012, 157, 383-390.

[63] K. Chaturvedi, K. Ganguly, M. N. Nadagouda, T. M. Aminabhavi, Journal of Controlled Release 2013, 165, 129-138.

[64] P. Mukhopadhyay, K. Sarkar, M. Chakraborty, S. Bhattacharya, R. Mishra, P. P. Kundu, Materials Science and Engineering: C 2013, 33, 376-382.

[65] W. E. Rudzinski, T. M. Aminabhavi, International Journal of Pharmaceutics 2010, 399, 1-11.

[66] C. Vauthier, C. Zandanel, A. L. Ramon, Current Opinion in Colloid \& Interface Science 2013, 18, 406-418.

[67] F. S. M. Tekie, M. Kiani, A. Zakerian, F. Pilevarian, A. Assali, M. Soleimani, R. Dinarvand, E. Arefian, A. Atashi, M. Amini, F. Atyabi, Carbohydrate Polymers 2017, 159, 66-75.

[68] Y.-Z. Du, Q. Weng, H. Yuan, F.-Q. Hu, ACS Nano 2010, 4, 6894-6902.

[69] K. R. Kamath, K. Park, Polymer Gels and Networks 1995, 3, 243-254.

[70] F.-M. Chen, H. Lu, L.-A. Wu, L.-N. Gao, Y. An, J. Zhang, Biomaterials 2013, 34, 6515-6527.

[71] S. R. V. Tomme, M. J. van Steenbergen, S. C. D. Smedt, C. F. van Nostrum, W. E. Hennink, Biomaterials 2005, 26, 2129-2135.

[72] A. V. Kühn, J.-H. Ozegowski, G. Peschel, R. H. H. Neubert, Carbohydrate Research 2004, 339, 2541-2547. 
[73] E. Esposito, E. Menegatti, R. Cortesi, International Journal of Pharmaceutics 2005, 288, 35-49.

[74] S. J. Kim, S. K. Hahn, M. J. Kim, D. H. Kim, Y. P. Lee, Journal of Controlled Release 2005, 104, 323335.

[75] A. Kumar, B. Sahoo, A. Montpetit, S. Behera, R. F. Lockey, S. S. Mohapatra, Nanomedicine: Nanotechnology, Biology and Medicine 2007, 3, 132-137.

[76] Y. Chi, X. Yin, K. Sun, S. Feng, J. Liu, D. Chen, C. Guo, Z. Wu, Journal of Controlled Release 2017, 261, 113-125.

[77] "Hyaluronic Acid-Based pH-Sensitive Polymer-Modified Liposomes for Cell-Specific Intracellular Drug Delivery Systems | Bioconjugate Chemistry," can be found under https://pubs.acs.org/doi/abs/10.1021/acs.bioconjchem.7b00551, n.d.

[78] J. Venkatesan, I. Bhatnagar, P. Manivasagan, K.-H. Kang, S.-K. Kim, International Journal of Biological Macromolecules 2015, 72, 269-281.

[79] H. H. Tønnesen, J. Karlsen, Drug Development and Industrial Pharmacy 2002, 28, 621-630.

[80] M. C. Peters, B. C. Isenberg, J. A. Rowley, D. J. Mooney, Journal of Biomaterials Science, Polymer Edition 1998, 9, 1267-1278.

[81] S. Y. Rabbany, J. Pastore, M. Yamamoto, T. Miller, S. Rafii, R. Aras, M. Penn, Cell Transplantation 2010, 19, 399-408.

[82] K. Bowey, B. E. Swift, L. E. Flynn, R. J. Neufeld, Drug Development and Industrial Pharmacy 2012, 39, 457-465.

[83] T. Suksamran, P. Opanasopit, T. Rojanarata, T. Ngawhirunpat, U. Ruktanonchai, P. Supaphol, Journal of Microencapsulation 2008, 1-8.

[84] A. Sharma, A. Gupta, G. Rath, A. Goyal, R. B. Mathur, S. R. Dhakate, Journal of Materials Chemistry B 2013, 1, 3410.

[85] G. Mahidhara, R. K. Kanwar, J. R. Kanwar, International Journal of Nanotechnology 2012, 9, 942.

[86] G. Han, Q. Chen, F. Liu, Z. Cui, H. Shao, F. Liu, A. Ma, J. Liao, B. Guo, Y. Guo, F. Wang, P. Ling, X.

Mei, Carbohydrate Polymers 2017, 164, 386-395.

[87] S. Dumitriu, Advanced Drug Delivery Reviews 1998, 31, 223-246.

[88] U. Bertram, R. Bodmeier, European Journal of Pharmaceutical Sciences 2006, 27, 62-71.

[89] J. N. BeMiller, in Carbohydrate Chemistry for Food Scientists, Elsevier, 2019, pp. xi-xii.

[90] J. L. Slavin, in Biochemical, Physiological \& Molecular Aspects of Human Nutrition, Elsevier, 2012.

[91] R. Pawar, W. Jadhav, S. Bhusare, R. Borade, S. Farber, D. Itzkowitz, A. Domb, in Natural-Based Polymers for Biomedical Applications, Elsevier, 2008, pp. 3-53.

[92] K. Yu, S.-L. Deng, T.-C. Sun, Y.-Y. Li, Y.-X. Liu, Molecules 2018, 23, 447.

[93] Z. Rudzki, S. Jothy, Mol Pathol 1997, 50, 57-71.

[94] V. Palla, Minerva ginecologica 1953, 5, 333.

[95] D. D. Dziewiatkowski, Biophysical Journal 1964, 4, 215-238.

[96] Y. H. Chung, T. K. Park, S. H. Yim, J. H. Lee, J. S. Bang, Y. K. Shin, J. Bae, S. S. Sim, K. W. Hwang, C. Y. Shin, W. J. Im, P. P. Khin, J. Lee, Y. S. Min, J. H. Jeong, U. D. Sohn, Journal of Medicinal Food 2019, 22, 355-364.

[97] B. C. WEXLER, A. E. DOLGIN, E. W. TRYCZYNSKI, Endocrinology 1957, 61, 300-308.

[98] Y.-S. Wang, C.-Y. Shen, J.-G. Jiang, Pharmacological Research 2019, 150, 104520.

[99] Z.-M. Li, N. Liu, Y.-P. Jiang, J.-M. Yang, J. Zheng, M. Sun, Y.-X. Li, T. Sun, J. Wu, J.-Q. Yu, ChemicoBiological Interactions 2019, 297, 119-129. 
[100] Z. Ze-fei, Z. Yong-ju, G. U. Ming-jun, JOURNAL OF SHANGHAI JIAOTONG UNIVERSITY (MEDICAL SCIENCE) 2013, 33, 607.

[101] Z. He, F. Lv, Y. Gan, J. Gu, T. Que, International Journal of Polymer Science 2018, 2018, 1-7.

[102] W. Y. Kim, J. B. Lee, H. Y. Kim, P. J. Park, S. P. Jung, H. Y. Lee, J.-G. Cho, K. S. Park, M. J. Cho, International Surgery 2019, 103, 452-460.

[103] E. A. Friedman, JAMA: The Journal of the American Medical Association 1980, 244, 2310-2311.

[104] A. S. Geara, M. R. Castellanos, C. Bassil, G. Schuller-Levis, E. Park, M. Smith, M. Goldman, S. Elsayegh, Clinical and Developmental Immunology 2010, 2010, 1-10.

[105] C.-H. Chen, L. Kang, H.-C. Lo, T.-H. Hsu, F.-Y. Lin, Y.-S. Lin, Z.-J. Wang, S.-T. Chen, C.-L. Shen, Journal of Agricultural and Food Chemistry 2015, 63, 9232-9238.

[106] H. Peng, M. Yang, Q. Guo, T. Su, Y. Xiao, Z.-Y. Xia, Cell Proliferation 2019, 52, DOI 10.1111/cpr.12624.

[107] R. S. JONES, Y. C. MAYNE, Endocrinology 1957, 61, 197-203.

[108] A. J. Barrett, C. B. Sledge, J. T. Dingle, Nature 1966, 211, 83-84.

[109] A. P. Petrov, N. V. Molodtsov, Problemy endokrinologii 1978, 24, 99.

[110] M. Yang, J. Ding, X. Zhou, X. Zhang, H. Tao, Y. Wang, G. Li, Biomedical Reports 2014, 2, 687-692.

[111] S. K. Pathak, M. M. Farooqui, A. Prakash, P. Kumar, Indian Journal of Small Ruminants (The) 2015, 21, 296.

[112] Ganesan, Xu, Molecules 2019, 24, 2556.

[113] X. Jiang, W. Meng, L. Li, Z. Meng, D. Wang, Frontiers in Pharmacology 2020, 11, DOI 10.3389/fphar.2020.00168.

[114] H.-Z. Liu, Y.-X. Tao, P. Luo, C.-M. Deng, Y.-P. Gu, L. Yang, J.-P. Zhong, Journal of Agricultural and Food Chemistry 2016, 64, 5759-5766.

[115] Y. Wu, C. Liang, T. Liu, Y. Liang, S. Li, Y. Lu, J. Liang, X. Yuan, C. Li, S. Hou, X. Lai, Biomedicine \& Pharmacotherapy 2018, 101, 953-960.

[116] Y. Wang, J. Wu, Y. Li, X. Qi, Evidence-Based Complementary and Alternative Medicine 2019, 2019, 1-8.

[117] J. Qu, Y. He, Y. Shi, L. Gai, L. Xiao, F. Peng, Z. Li, X. Wang, C. Yuan, Journal of Cellular and Molecular Medicine 2020, 24, 8115-8125.

[118] Y. Guo, Z. Zhang, Z. Wang, G. Liu, Y. Liu, H. Wang, Bioscience Reports 2020, 40, DOI 10.1042/bsr20193396.

[119] Q. Luo, Z. Li, X. Huang, J. Yan, S. Zhang, Y.-Z. Cai, Life Sciences 2006, 79, 613-621.

[120] X. Lei, P. Huo, Y. Wang, Y. Xie, Q. Shi, H. Tu, J. Yao, Z. Mo, S. Zhang, Frontiers in Endocrinology 2020, 11, DOI 10.3389/fendo.2020.00164.

[121] G.-J. Shi, J. Zheng, J. Wu, H.-Q. Qiao, Q. Chang, Y. Niu, T. Sun, Y.-X. Li, J.-Q. Yu, Food \& Function 2017, 8, 1215-1226.

[122] X. Y. Le, P. Luo, Y. P. Gu, Y. X. Tao, H. Z. Liu, Bratislava Medical Journal 2015, 116, 334-339.

[123] I. B. Campos, M. Herd, K. L. Moffitt, Y.-J. Lu, M. Darrieux, R. Malley, L. C. C. Leite, V. M. Gonçalves, Vaccine 2017, 35, 1306-1315.

[124] S. Dzanibe, S. A. Madhi, Expert Review of Vaccines 2018, 17, 635-651.

[125] N. B. Mirza, I. A. Wamola, B. A. Estambale, E. Mbithi, M. Poillet, East Afr Med J 1995, 72, 162164.

[126] Z. Huo, J. Miles, T. Harris, P. Riches, Vaccine 2002, 20, 3532-3534.

[127] S. M. Zimmer, D. S. Stephens, Expert Opinion on Pharmacotherapy 2004, 5, 855-863. 
[128] J. C. Paton, C. Trappetti, Microbiol Spectr 2019, 7, DOI 10.1128/microbiolspec.GPP3-0019-2018.

[129] K. L. Dobrochaeva, N. R. Khasbiullina, N. V. Shilova, P. S. Obukhova, Y. A. Knirel, A. Y. Nokel, N. V. Bovin, Mol Immunol 2019, 106, 63-68.

[130] V. F. Santana, Y. V. Balbin, J. C. Calderón, L. P. Icart, V. Verez-Bencomo, n.d., 25.

[131] C. Janis, A. J. Grant, T. J. McKinley, F. J. E. Morgan, V. F. John, J. Houghton, R. A. Kingsley, G. Dougan, P. Mastroeni, Infect Immun 2011, 79, 2481-2488.

[132] C. C. Daniels, P. D. Rogers, C. M. Shelton, The Journal of Pediatric Pharmacology and Therapeutics 2016, 21, 27-35.

[133] M. C. J. Maiden, in Hot Topics in Infection and Immunity in Children (Eds.: A.J. Pollard, G.H. McCracken, A. Finn), Springer US, Boston, MA, 2004, pp. 23-29.

[134] L. Lin, M. Qiao, X. Zhang, R. J. Linhardt, Carbohydrate Polymers 2020, 230, 115643.

[135] H. Peltola, Clin Microbiol Rev 2000, 13, 302-317.

[136] T. Wuorimaa, H. Käyhty, Scandinavian Journal of Immunology 2002, 56, 111-129.

[137] M. Arcuri, R. Di Benedetto, A. F. Cunningham, A. Saul, C. A. MacLennan, F. Micoli, PLoS One 2017, 12, DOI 10.1371/journal.pone.0189100.

[138] K. L. O'brien, M. C. Steinhoff, K. Edwards, H. Keyserling, M. L. Thoms, D. Madore, The Pediatric Infectious Disease Journal 1996, 15, 425-430. 